\title{
Protecting New Plant Varieties in China and Its Major Problems
}

\author{
Yangkun Hou
}

\begin{abstract}
China has achieved remarkable results for the protection of new plant varieties since it promulgated and implemented "Regulations for the Protection of New Plant Varieties" in 1997. However, as a whole, the level of legislation is still at an early stage, primarily referencing to the UPOV Convention and the legal content of other countries. The legislation has not yet set up the ultimate goal and reasonable protection measures that would meet China's current actual needs. The chapter discusses the status of protection of new plant varieties in China and characteristics. It then analyzes the major deficiencies and shortcomings of existing laws and explores the main reasons behind. This chapter proposes a number of specific measures for perfecting the legal system for the protection of new plant varieties in China before it ends with a conclusion.
\end{abstract}

Keywords

New plant variety $\cdot$ UPOV $\cdot$ Variety name rights $\cdot$ Breeder's right

\section{Status of Protection of New Plant Varieties in China}

\subsection{The General Background}

China is one of the oldest civilizations in the world and has a vast territory. From north to south, it spans the cold temperate zone, temperate zone, warm temperate zone, subtropical zone, and tropical zone. There is a large variety of plants growing on this vast land. According to scientific investigation, there are more than 30,000

Y. Hou (四)

School of Law Beijing Institute of Technology, Beijing, China 
kinds of higher plants in China, ranking third after Brazil and Colombia. This rich plant resource has laid a solid foundation for the cultivation of new plant varieties in China and for the enhancement of the protection of new plant varieties.

In the long historical development of China, the hardworking and wise Chinese farmers have domesticated and cultivated a large number of plant species and applied them to agricultural production. In modern breeding, workers continue to cultivate a large number of new varieties. Since the founding of the People's Republic of China (PRC) in 1949, China's crop varieties have been updated for several generations, which have made important contributions to China's improving varieties and increasing yields. In particular, Academician Yuan Longping, the father of the well-known rice breeding in China, has made outstanding contributions to the world's breeding business and helped solving the basic human need for food.

Under the background of this breeding history and breeding scale, China promulgated the Regulations for the Protection of New Plant Varieties in 1997 and began to introduce and implement a legal system for the protection of new plant varieties in China, which has its origin in the 1941 Breeders Ordinance of the Netherlands. Its central content is the protection of breeder rights, which enables breeders to derive economic benefits from the commercial exploitation of new plant varieties. Obviously, the value objective established by this legal system is mainly to obtain personal economic benefits through legitimate breeding labor ${ }^{1}$. However, the problem that is difficult to avoid is that compared with the "collectivism" and "devotion spirit" advocated and implemented in China since 1949, emphasis on the "pursuit of purely personal economic interests" is unlikely to take root in China due to its ancient and profound social tradition. ${ }^{2}$

Since the promulgation and implementation of the "Regulations for the Protection of New Plant Varieties" in 1997, China has made huge progress and achievements in the legislation for the protection of new plant varieties. The National People's Congress Standing Committee, the Supreme People's Court, the Ministry of Agriculture and Rural Affairs, and the National Forestry and Grassland Administration have all played a role. In the revision of the Seeds Law in 2015, a section on the protection of new plant varieties was added; and the Supreme People's Court has promulgated the judicial interpretation to specifically deal with this issue. The agriculture and forestry departments have promulgated respective regulations,

\footnotetext{
${ }^{1}$ Internationally, this legal system for the protection of new plant variety rights was established by the International Convention for the Protection of New Plant Varieties (UPOV Convention), which was established in 1961. After three revisions in 1972, 1978, and 1991, there are now three valid texts: the 1961/1972, 1978, and 1991 texts. As of June 2018, the UPOV Convention has 75 member states. Only Belgium is applying the 1961/1972 text, 17 countries are applying the 1978 text, and the remaining 57 countries are applying the 1991 text. China joined the 1978 text in 1999.

${ }^{2}$ In the traditional culture of China, people have advocated the spirit of "equality," "dedication," "mutual help," and "supremacy of national interests" and have not promoted, or have even opposed, the simple pursuit of economic wealth.
} 
including the "Implementation Rules for the Protection of New Plant Varieties," "Guidelines for the Examination of New Plant Varieties," "The Protection List of Plant Varieties," etc., which foresee the application, testing, authorization, review, and protection of new plant varieties and achieve basic complete coverage.

It is particularly worth noting that the Ministry of Agriculture and Rural Affairs has also issued the following important regulations, including "Nomenclature of Agricultural Plant Varieties," "Registration Guidelines for Non-major Crop Varieties," "Registration Measures for Non-major Crop Varieties," “The Measures for the Protection of Agricultural Wild Plants," and "Administrative Measures on Crop Germplasm Resources," which reflect the fact that the Ministry is continuously refining and improving this legal system.

\subsection{The Research Status of Protection of New Plant Varieties}

With regard to the research status of new plant varieties in China, the number of experts and scholars in China who study the protection of new plant varieties is very small. The main reasons for this are the following: (a) It is difficult for experts and scholars engaged in legal research to study this area in depth, as general legal knowledge is not enough and basic intellectual property legal knowledge is required. (b) Even experts and scholars who have mastered the knowledge of intellectual property law are unable to systematically study this area and can only understand the legal system from the literal meaning of the law and general social common sense, if they do not have expertise in biology, genetics, and breeding. (c) The number of legal cases in this area is still small compared with the cases of copyright, patents, and trademarks and has not attracted much attention.

Although Chinese scholars began to explore and discuss the issue of the protection of valuable non-plant new varieties, essentially derived varieties, criminal liability for infringement breeders' rights, reasonable damages, range of special rights of farmers, and the establishment of special variety name rights in legislation. At present, research in China on the protection of new plant varieties is still mainly to learn and understand the basic content of the UPOV Convention and other national laws. China has yet to establish its own DUS (the Examination of Distinctness, Uniformity and Stability) test guide and genetic fingerprint data for plant varieties and to integrate the scientific spirit of this legal system into the inner spirit of the Chinese nation. The research on this legal system still faces the following problems that need to be solved: What is the goal that should be pursued in this legal system? What specific contents should be included in it? How could this legal system be improved according to China's characteristics in plant resources and cultural and social development and from the long-term and overall perspectives? How can this legal system serve Chinese people and people of the world better? At present, there is basically little or no research on these deeper and broader issues in China. 


\subsection{Granting of Breeders' Rights in China}

\subsubsection{The Total Number of Breeders' Rights Granted in China by June 2018}

China has accepted and approved breeders' rights since 1999. This work is handled by the Ministry of Agriculture and Rural Affairs (formerly the Ministry of Agriculture) and the National Forestry and Grassland Administration (formerly the State Forestry Administration). According to the statistics of the relevant departments of the Ministry of Agriculture and Rural Affairs, by 2016, the number of applications for new plant variety rights in China already ranked first in the world. ${ }^{3}$ From 1999 to June 2018, China approved a total of 12,221 breeders' rights, of which 10,863 are for agriculture and 1358 are for forestry (the author carried out calculations based on the statistics and information published on the official website of the Ministry of Agriculture and Rural Affairs and the National Forestry and Grassland Administration).

\subsubsection{Period Needed for Applying for Breeders' Rights in China}

The average length of time from the application of a variety right to its acquisition in China varies, which can range from about 10 months to 9 years. For crops such as rice, corn, wheat, soybeans, and cotton, generally, it takes 3 to 4 years. Cases with delay of over 5 years may have encountered opposition, related litigation, or disputes during the application process. Since 2017, this period has been shortening. More and more breeders' rights on new plant varieties have been obtained within a period of less than 1 or 2 years.

\subsubsection{Foreign Applicants Obtaining Breeders' Rights in China}

The majority of breeders' rights holders are Chinese units and individuals. A small number of foreign units and individuals have also been applying for breeders' rights in China. Until 2018, foreign applications mainly come from the United States, Germany, France, the United Kingdom, the Netherlands, Belgium, Italy, Denmark, Japan, Switzerland, and New Zealand. Among these, the United States, the Netherlands, France, Germany, the United Kingdom, and Switzerland have obtained the most breeders' rights.

From 1999 to June 2018, 188 forestry breeders' rights in China were obtained by foreign applicants from nine countries, accounting for $13.84 \%$ of the total forestry breeders' rights. In the category of agricultural breeders' rights, the proportion of breeders' rights acquired by foreign units and individuals is smaller. In addition, due to the different types of varieties, it is difficult to compare the commercial advantages of breeders' rights for different owners. According to the statistics of the

\footnotetext{
${ }^{3}$ According to Zhang Yanqiu, the number of applications for breeder's rights in China in 2016 has doubled from 5 years ago (in Chinese), available at http://finance.china.com.cn/ news/20171013/4413049.shtml (accessed 2018-04-16).
} 
National Forestry and Grassland Administration, as of the end of 2016, the top ten units that have obtained forestry breeders' rights in China are Beijing Forestry University; Chinese Academy of Forestry; Shandong Academy of Forestry; Kunming Yang Yueji Horticulture Co., Ltd.; Chinese Academy of Sciences; Shandong Agricultural University; W. Korder' Sohne (Germany); Shanghai Botanical Garden; Palm Garden Co., Ltd.; and Meilland International SA (France). ${ }^{4}$

\subsubsection{Commercial Use of Breeders' Rights in China}

At present, the economic significance and commercial value of the new plant varieties in China are mainly reflected in the fact that the breeders' rights holders prohibit others from commercializing the authorized varieties and less in the use of these exclusive rights to gain commercial interests. In addition, breeders can also obtain benefits through cooperative breeding with others, or commissioned breeding for others, and licensing others to use their authorized varieties, or selling the application right of breeders' rights or the breeders' rights. Finally, under China's current legal provisions, breeder rights holders can also use the variety rights as capital contributions, or mortgages, and can also use breeder rights for financing. However, so far, such activities are still in their infancy in China.

\subsection{Chinese Applying for Breeders' Rights with Foreign Countries: Extremely Rare}

The number of Chinese individuals and units applying for new plant variety rights with foreign countries is very small. From 2000 to 2013, Chinese applicants filed for a total of 133 applications with different foreign countries, obtaining 47 authorizations in aggregate. In 2013, Chinese applicants submitted a total of 33 applications overseas and obtained 5 authorizations. In 2014, a total of two applications were filed with different foreign countries and one authorization was obtained. In other words, Chinese breeders mainly apply for breeders' rights in China and rarely pay attention to applying abroad. The main reason for this situation may be that Chinese seed companies mainly engage in commercial activities related to the seed industry in China and have not expanded their activities overseas.

\section{Types of Disputes Occurred in China}

Chinese courts now mainly hear the following types of cases.

\footnotetext{
${ }^{4}$ Intellectual Property Research Center of State Forestry Administration. Forestry plant new varieties, http://www.cfip.cn/yjzx/SecondBrw.cbs?ResName=lyzs\&RC=95\&order $=94 \&$ ResultFile $=c \%$ 3A\%5Ctemp\%5Ctbs\%5CF249824\%2Etmp\&SortFld=\&sortorder=
} 


\subsection{Dispute Over Ownership and the Right to Apply for Breeders' Rights}

Cases include Tian Qingyi v. Zhongzhong Group Chengde Great Wall Seed Co., Ltd. (Civil Judgment of the Intermediate People's Court of Shijiazhuang City, Hebei Province (2005), Shi Min Wu Chu Zi No. 00176); Shenyang Agricultural University v. Du Mingqi, etc. (Civil Judgment of the Higher People's Court of Liaoning Province (2005), Liao Min Si Zhong Zi No. 73); and Wang Tengjin and Liu Zhenzhuo v. Sichuan Zhongzheng Science and Technology Seeds Co., Ltd., and Guangxi Bobai County Agricultural Science Institute (Civil Judgment of the Nanning Intermediate People's Court of Guangxi Zhuang Autonomous Region (2006), Nanning Min San Chu Zi No. 9).

\subsection{Infringement of Breeder's Rights}

There are currently six types of cases that infringe on a breeder's rights in China.

\subsubsection{Fabricating a Variety Name}

In this type of infringement, the infringer produces and sells another person's authorized variety, but deliberately uses another name to replace the name of the authorized variety. The name used by the infringer may be the real name of another breed or may be a false name that was arbitrarily fabricates and does not exist at all. Currently, this is a major type of infringement in China. In the production and management of the seed industry, people generally refer to this type of infringement as "brand counterfeit." For example, in the case of Dunhuang Seed Industry Pioneer Seed Co., Ltd. v. Xinjiang Xinteli Seed Co., Ltd. and the Fourth Group of the First Agricultural Division of the Xinjiang Production and Construction Corps (Civil Judgment of the Supreme People's Court (2014) Min Ti No. 26.), the name of the plaintiff's authorized variety was "Xianyu 335," but the defendants replaced it with "Xianyu 696" and produced and sold it. "Xianyu 696" was a false name arbitrarily fabricated by the defendants. The court ruled that the defendants constituted an infringement according to Article 6 of The Regulations on the Protection of New Varieties of Plants (2014 Revision) and should assume tort liability 5 .

\subsubsection{Forging or Imitating Another Person's Authorized Variety}

In this type of infringement, another variety is used as impostor of another person's authorized variety. The basic feature of this type of infringement is using variety B,

\footnotetext{
${ }^{5}$ Article 6 of the Regulations on the Protection of New Varieties of Plants provides: The unit or individual that completes the breeding shall enjoy exclusive rights to its authorized varieties. No unit or individual may produce or sell the propagation material of the authorized variety for commercial purposes without the permission of the owner of the variety right and may not reuse the propagation material of the authorized variety for the production of propagation material of another variety for commercial purposes. However, unless otherwise provided by this Ordinance.
} 
either legally owned by the infringer or a third party, and passing it off as authorized variety $\mathrm{A}$. The variety produced and sold is nominally the authorized variety $\mathrm{A}$, but is actually variety B. There are two specific ways of implementing specific torts: directly forging the denomination and packaging of an authorized variety to carry out production and sales activities and imitating the name of an authorized variety or its external packaging. For this type of infringement, some breeder's rights holders are unwilling to sue publicly because they fear that once people know that there are fake varieties of their breeds, their normal sales will be affected. Therefore, fewer cases of this type have been brought to court.

\subsubsection{Unauthorized Use of Authorized Varieties of Others}

Currently in China this is also an important type of infringement, which involves producing and selling authorized varieties belonging to others for commercial purposes without obtaining the permission of the right holders. Unauthorized here includes the following: no authorization was ever obtained (Guo 2006); authorization obtained, but expired or terminated ${ }^{6}$, or the authorized geographical scope or time range was exceeded (Yangkun, 2015); and unauthorized permission by third party (Hou 2017).

\subsubsection{Plundering Others' Right to Apply for Breeder's Rights}

This type of infringement is a direct plunder of other people's breeding achievements. The infringement usually takes place in employment breeding - often occurs after employees have retired, resigned, or switched to other companies - commissioned breeding, and cooperative breeding. Infringers often deliberately violate the working regulations or the agreement of the parties, thus illegally utilizing the breeding results. An example in point is the abovementioned Wang Tengjin and Liu Zhenzhuo v. Sichuan Zhongzheng Technology Co., Ltd., and others, where the defendant used the opportunity to help the plaintiff submit the application materials to the relevant government agency and took the new plant variety cultivated by the plaintiff as his own, applying for the breeder's right as the applicant. After finding out the facts, the court ruled that the defendant's ill-gotten breeder's rights should be transferred back to the plaintiff.

\subsubsection{Stealing Others' Authorized Varieties}

The typical method of infringement is direct theft of the breeding materials for authorized varieties of others. These are generally stolen from the fields where reproduction occurs or from the households of farmers or purchasers who are entrusted with reproduction. The number of varieties obtained by this type of theft

\footnotetext{
${ }^{6}$ Sichuan Zhong Zheng Technology Co., Ltd. v. Guangxi Zhuang Autonomous Region Bobai County Institute of Agricultural Sciences and others by the Guangxi Zhuang Autonomous Region Higher People's Court (2017), Gui Min Zong 95 civil judgment, in which the defendant's act of producing and selling authorized varieties after the termination of the license contract was ruled to be constituting infringement, see the Supreme People's Court, Top 10 Intellectual Property Cases in 2017, available at http://www.court.gov.cn/zixun-xiangqing-91312.html.
} 
is relatively small. For example, Hainan Province is an important breeding base for new plant varieties in China. Many breeding workers in the northern provinces generally need to go to Hainan to speed up their breeding progress; there, they can increase the planting period from one season to two seasons annually. During this process, pirates steal the seedlings or seeds of new plant species cultivated by others from the fields and then use them as their own breeding materials to breed their own new varieties.

It is very regrettable that China does not have any special provisions for such theft. It can only be dealt with in accordance with the Criminal Law promulgated and implemented in 1997. However, according to the provisions of the Criminal Law, the police can only file a case when the value of the stolen goods reaches a certain amount, and yet the value of small amount of breeding materials stolen is difficult to specify. Therefore, we have not yet seen charges against such a theft, which has led to the widespread occurrence of theft of breeding materials in Hainan. However, in the past 2 years, the Chinese government begun to pay attention to this situation and strengthen the management of the breeding base in Hainan.

\subsubsection{Using Essentially Derived Varieties}

This type of infringement involves using other people's authorized varieties for modified breeding, that is, only adding or modifying a small portion of genetic traits, without changing the main genetic traits of the original varieties, so as to obtain an essentially derived variety. Although the essentially derived varieties may have some differences in form from the original varieties, the basic traits of the varieties are basically the same, and the infringers used the essentially derived varieties to commit infringement. This use of the breeding technology to hide the infringement still amounts to a kind of tort.

After obtaining essentially derived varieties, the infringers would often apply for breeder's rights on them; once obtaining the breeder's rights, the infringers will be entitled to "frankly and squarely" and "legally" produce and sell the essentially derived varieties, achieving infringement of the varieties of others through legal means. Another way to commit infringement is through use of essentially derived varieties for commercial activities, without applying for breeder's rights. During litigation, the appraisal technology may determine that the derived variety is distinct from the actually infringed authorized variety, thereby avoiding the possibility of being identified as a tort.

It is a great pity that the "essentially derived varieties" clause, which is in the UPOV Convention's 1991 text, was not included in the 1978 text in that China is now participating. Therefore, in China, there is no concept of "essentially derived varieties" in the law, so there have so far been no cases or court decisions in China concerning "essentially derived varieties."

However, since China already has advanced breeding technology, it is not a difficult task for many breeding units to cultivate "dependently derived varieties" purposefully. In fact, many "essentially derived varieties" have been cultivated, widely produced, and sold. The current outstanding problem is that there is a lack of legislation to deal with the reality. 


\subsection{Contract Disputes for New Plant Varieties}

There are mainly three types of contract disputes in China.

\subsubsection{Over Commissioning Production Seeds}

A variety owner, or licensed manufacturer and seller, needs to produce an authorized variety in order to sell it. In reality, they generally need to entrust the farmer or the farm to produce the authorized variety, and the two parties need to sign a contract entrusting the farmer with production. There are also frequent disputes in the performance of such contracts.

There are two types of such disputes: one is simply an ordinary dispute between the two parties and the other is due to the fact that the entrusting party illegally produces an authorized variety of others, causing infringement of the breeder's rights of others, resulting in inability to continue fulfilling the signed contract.

One such case is Henan Golden Dr. Seed Industry Co., Ltd. v. Jiaozuo Bonon Seed Co., Ltd.; see Civil Judgment of Henan Higher People's Court (2006), Yu Fa Min San Zhong Zi No. 38. ${ }^{7}$ The plaintiff signed an entrustment contract with the defendant and entrusted the defendant to produce wheat seeds. However, the defendant did not produce the quantity agreed in the contract, and a dispute between the two parties occurred. Finally, the court ruled that the defendant bore legal responsibility.

\subsubsection{Arising from Transfer Contract or License Contract}

In a dispute over a transfer contract, there are two types, namely, dispute over a contract transferring the right to apply for breeder's rights and dispute over a contract transferring the breeder's rights. In China, disputes based on transfer contracts and licensing contracts are common. An example is the case of Jiangsu Suke Seed Industry Co., Ltd. v. Jiangsu Siyuan Seed Industry Technology Co., Ltd. (Civil Judgment of Jiangsu Higher People's Court (2008), Su Min San Zhong Zi No. 0051). The defendant failed to fulfill the contract for the transfer of the right to operate the breeder's right signed by the two parties, and the court ruled that the defendant was legally liable.

\subsubsection{Over Contracts on Breeding New Plant Varieties}

Such contract disputes sometimes involve the issue of the ownership of breeder's rights, and some involve only the issue of simply performing the contract. An example is the case of Sichuan Agricultural University Hi-Tech Agriculture Co., Ltd. v. Mianyang Xiannong Seed Industry Co., Ltd. and the third person Sichuan Agricultural University; see Sichuan Chengdu Intermediate People's Court Civil Judgment (2003) Cheng Min Chu Zi No. 926. Although the defendant actually participated in the breeding work of the plaintiff, it only provided financial support and assistance, and the ownership of the new variety was not clearly stipulated in the cooperative breeding contract. The court ruled that the new variety belonged only to the plaintiff.

\footnotetext{
${ }^{7}$ Available at the website of the Supreme People's Court of the PRC: http://ipr.chinacourt.org/ public/detail_sfws.php?id=11919.[2007-11-29/2010-05-03]
} 


\section{$3 \quad$ Major Deficiencies and Shortcomings of Existing Laws}

Although China's legislative work has achieved remarkable results, China's legislation on the protection of new plant varieties clearly has the following defects and deficiencies due to the influence and constraints from various factors.

\subsection{Overall Lower Level of Protection}

Since China has acceded to the 1978 Act of UPOV Convention, the text of the Convention restricts the current legislation in China. This situation has made China's level of protection of new plant varieties as a whole relatively low. This kind of legislative backwardness is mainly reflected in the following two aspects: (a) The content of breeder's rights is too thin and simple. On the one hand, it only provides protection of propagation materials and does not involve harvested materials and their direct products; on the other hand, it lacks provisions on the essentially derived varieties, leaving room for this important type of infringement. (b) Tort liability is too simple and backward for two reasons. One is the absence of specific legal provisions for criminal responsibility in legislation, and the other is that there are only three categories of civil tort liability: "stop infringement," "damage compensation," and "elimination of impact." And there is no scientific refinement of "damage compensation." Since the entire legislative content is both simple and backward, it has severely hampered the legitimate expectations and demands of breeder's rights holders and farmers. Obviously, this situation has not met the requirements of the times.

\subsection{Serious Disconnect Between New Plant Varieties and Agricultural and Forestry Production}

Due to the lack of "practicability" requirements in the current conditions for the identification of new plant varieties in the law, some new plant varieties for which breeder's rights have been granted, but they have no practical value in agricultural and forestry production, or they cannot meet the need for large-scale agricultural cultivation. This makes these new varieties not useable in actual production. Obviously, as these new plant varieties can serve as breeding material for breeding work, they may still have some value during the breeding process. However, from the perspective of the agricultural production, these new plant varieties should not be eligible for, and therefore, should not be granted breeder's rights.

Of course, in China's legislation, the conditions for the establishment of "new plant varieties" are based on the provisions of the UPOV Convention. In terms of form, Chinese legislators should not bear any responsibility for this. However, because these conditions do not meet the actual needs of Chinese society, Chinese legislators have the responsibility to modify and improve such conditions to make them more scientific and reasonable. 
This involves a more in-depth issue. What is the purpose of establishing a legal system for the protection of new plant varieties? What do we want to achieve? Or is it that we are mainly to meet the requirements of developed countries that require us to establish such laws? Obviously, for this issue, the answer can be easily reached from a simple logical relationship and the literal meaning of the current law: "Protection of breeder's rights and promotion of breeding development." However, this answer faces two problems: (A) In reality, to what extent can the existing legislative content guarantee the realization of the above objectives, or rather, how far has the current legislative content deviated from the way in which the above objectives can be truly achieved? (B) In addition to the current legislative model and legislative content, is there a more scientific and reasonable legislative model and legislative content? Of course, people may find it hard to answer these questions. Many people may not have thought about these issues yet.

\subsection{The Social Effects of the Existing Legislative Content Are Not Ideal}

Over the years, through the implementation of laws for the protection of new varieties of plants, it has always been better for society to promulgate and enforce certain laws than to lack them. However, the objective reality that cannot be overlooked is that the new plant variety infringement activity in China has been relatively common, and it has been fairly serious in some provinces. In addition to infringing on breeders' rights, there are also a large number of counterfeit seeds that have caused considerable harm to farmers. This fact fully demonstrates that there is still a significant gap between the existing legislation on the protection of new plant varieties and the social reality of China.

In addition, using existing legal provisions to implement rights protection, especially the use of judicial means to protect rights, is not only complicated and costly, but the end result is often disappointing to the plaintiff. The main reason is that the tort liability that the infringer ultimately assumes is likely to be much lower than the actual illegal gains. The plaintiff has to bear additional costs in order to safeguard his rights. However, in the end, there is still no reasonable compensation or reasonable compensation that can actually be obtained. This situation has objectively encouraged infringers to continue recklessly.

\section{$4 \quad$ Main Reasons Affecting the Protection of New Plant Varieties}

\subsection{The Influence and Role of Social Status on Legal Status}

There are two main factors affecting China's legal system for the protection of new plant varieties: (a) the state of the society in which the legal system is located and (b) the state of the law, including the status of legal research, the level of legislation, and the level of justice. 
Among these two reasons, the state of society is the basis of the state of law and plays a decisive role in the state of law. The state of law is subject to the state of society. Just like the relationship between land and crops, the social state of a country in a certain historical period is like a piece of land, and the specific legal status is like crops growing on this land. Some crops are suitable for planting here, others are not; whether a crop can be harvested, eventually, to a large extent depends on the characteristics of the land and the adaptability of the crop itself.

\subsection{Social Status and Legal Status Reflected in the Legislation and Enforcement of New Plant Varieties}

\subsubsection{Treating New Plant Varieties Simply as an Ordinary Commodity}

In the existing theoretical research, legislation and enforcement of protection of new plant varieties, people generally regard new plant varieties as a kind of seed that can be produced and sold just like any commodity, and the breeder's right is only an intellectual property right that belongs to the category of civil rights. Almost completely ignored is its close relation to the national genetic resources, ecological environment, biodiversity, and food safety on which we all depend.

What should be seen is that no matter how advanced science and technology is, and no matter how amazing the technological products created by human are, there is one thing that human beings cannot detach themselves from, that is, we are part of the biological world. We need to guarantee the existence and continuation of an ecological environment in which we live. As a result, it is unscientific to disregard the genetic resources involved in new plant varieties, which cannot be treated as a pure economic issue.

\subsubsection{Some Law Has Fallen into the Shadow of Foreign Law}

Under the framework of the TRIPS Agreement, every sovereign state should ask itself what the ultimate purpose of its legal protection of plant breeder's rights should be. Obviously, the ultimate goal in China should be to solve the problems that have occurred or will occur in China's reality. However, for many years, the jurisprudence in China has been gradually dissociating from or ignoring China's actual situation and instead blindly following foreign legal provisions and their literal meanings, without being able to learn their core spirit.

The spirit of law is connected to the basic conditions of the country and society, which are the root cause of their survival and function. Unfortunately, some people apply the judgment made by a foreign court as a legal standard to interpret a domestic legal norm. In fact, this is a very unwise approach, because it is separated from the basic principle that the specific legal content needs to be combined with specific social soils.

Obviously, if the legal system for the protection of new plant varieties in China is to achieve true development and progress, it must emerge from the shadow of 
foreign laws, be based on in-depth investigation on China's basic national conditions, and absorb good legal concepts and provisions of foreign laws.

\subsubsection{The Spirit and Rationale of Law Are Affected by Times}

The mission of law is to pursue fairness and justice in human society, which in turn aims to firmly safeguard the interests of the vast majority of people, protect the interests of honest laborers, and foster the development and progress of society. Since the 1990s, great changes have taken place in China, and have been accompanied by widespread problems, including serious environmental pollution, food safety problems, counterfeiting of products, high housing prices, high school fees, expensive medical care, and lack of access to medical services. To this end, the Chinese government continues to take various measures, however with little improvement.

It is worth noting that these social issues have also had a significant impact and influence on China's legal sciences. First of all, the prominent and ubiquitous nature of these social issues is increasingly affecting people's normal lives. With the rising expenditures of people, pressure from life will make people feel that the relationship between them and society is almost one of money and economic interests. This will, to a certain extent, obscure people's understanding of the unifying ideals and goals that society should have. This will also force people to pay more and more attention to immediate and realistic economic interests. Obviously, this has deeply plunged people into the scope of a single economic interest and cannot take into account the personal spiritual interests and public interests of the entire society.

This situation is reflected in the field of law. Legal researchers, legislators, judges, lawyers, and administrative law enforcement officers are also ordinary members of society.

They must face the social problems that most ordinary people face, the actual feelings of the vast majority of ordinary people are also their actual feelings, and their actual feelings are that in the current Chinese society, economic interests are very important and even the only thing that is truly worth pursuing and getting for them. Therefore, economic interests should also become the main issue in the law, even the core issue. In this situation, the interests of the public, the interests of others, and the long-term development of society may be ignored, and in some cases, basic fairness and justice may even be bought off or subverted by the pursuit of economic benefits in the real world.

In short, due to the influence of the social environment, in the field of law, it is easy to deal with many things and many problems in society from an economic standpoint. It seems that everyone is mainly living for the money in front of them, and all of human society exists for the current economic benefits. Obviously, if this situation occurs in the field of law, it will be very regrettable. However, an unacceptable reality is that in the current social reality, this situation has been not only universally existed but also serious in some respects. At present, there are also such effects in the legal system for the protection of new plant varieties, that is, all the problems of protecting the breeders' right are simply attributed to an economic problem. 


\section{$5 \quad$ Measures Proposed for Perfecting the Protection of New Plant Varieties in China}

\subsection{Institutions Authorizing Breeder's Rights Should Be Unified}

At present, China's new plant variety authority is the Ministry of Agriculture and Rural Affairs and the State Forestry and Grassland Administration. Under this form, which set up Office for the Protection of New Varieties of Agricultural Plants and the Office for the Protection of New Varieties of Forestry Plants, respectively. These two offices have enacted their separate departmental regulations and management methods. Obviously, this model is very unscientific and unreasonable. The two agencies should be merged into one unified China Plant Variety Protection Office.

In addition, breeders' rights are granted by the Chinese government and embody a kind of national behavior under state sovereignty. Granting of such rights should not be done by different governance agencies. Just as it is not possible for a country to have two independent foreign ministries at the same time, there should not be two offices that grant breeders' rights.

\subsection{To Apply the 1991 UPOV Convention Text as Soon as Possible}

The prominent differences between the 1991 and 1978 UPOV Convention are the following two: (a) In terms of protected plant species, the 1978 text only requires the protection of some plant species, while the 1991 text requires the protection of all plant species. (b) The second is the content of breeders' rights. The 1991 text not only extends the scope of protection from simple reproductive materials to harvested materials and their direct products but also protects essentially derived variety. In addition, the social role of the breeders' rights is greatly improved and their protection enhanced. Based on China's abundant plant resources, current breeding level, and agricultural development level, China should apply the 1991 text of the UPOV Convention to better protect plant resources and promote the further development of breeding work.

\subsection{To Revise and Improve the Legal Regimes on New Plant Varieties}

The following modifications and improvements are proposed, which can be realized through revising the "Regulations on the Protection of New Plant Varieties" and (or) elevating the regulations into the level of a statutory law by People's Congress to better satisfy the requirement of rule of law. 


\subsubsection{To Set Up Special “Variety Name Rights”}

As mentioned above, there is no provision in the existing UPOV Convention, including the 1961/1972, 1978, and 1991 texts, or in the "Regulations for the Protection of New Plant Varieties" in China that recognizes the "variety name rights." The author proposes the introduction of such rights, either as a new power of the breeder's rights or independent of the breeder's rights. In addition, this author suggests that the variety name rights should not have a time limit for the protection period and that the "variety name rights" should include (i) the right to use the variety name in commercial activities, (ii) the right to use the variety name similar to the protected variety name, and (iii) the right to use this variety name on other goods and services.

\subsubsection{To Add the Requirement of Practicality as One Condition for Obtaining the Breeder's Rights}

As mentioned above, within the framework of the current UPOV Convention, varieties that have acquired breeder's rights may not have practical value in actual agricultural production. This is because there is no "practicality" requirement in the conditions of obtaining the breeder's rights. In particular, for some varieties, although the breeder's rights have been obtained, they are not allowed to enter agricultural production because of their obvious defects and bad characteristics. This has affected the role of the breeder's rights legal system, which in turn affects people's attitude toward the protection of breeder's rights.

Therefore, the "practicability" requirement should be added to the conditions of granting the breeder's rights. "Practicability" here includes two items: (i) If the variety belongs to the scope of China's variety certification, it should meet the basic conditions for the certification. (ii) If it does not belong to the scope of variety certification, it shall be able to satisfy the basic conditions for the variety to be planted in the field.

\subsubsection{To Establish a Professional Qualification Restriction System for Infringers}

At present, there are a large number of violations of breeder's rights through various channels and methods in China. In particular, due to the relatively light tort liability, some infringers have continued infringement after being punished by the law. Obviously, it is no effective deterrent effects. Therefore, the author proposes to increase legal responsibilities, including "professional responsibility," which would prohibit infringers from engaging in varieties breeding and seed production for a certain number of years. This kind of legal responsibility is commonly stipulated in

\footnotetext{
${ }^{8}$ The author has published a paper on this topic and related issues, see Yangkun Hou, On the Characteristics and Legal Functions of the Names of New Plant Varieties (in Chinese), Intellectual Property Rights, 2015(9):37-43.
} 
China's traffic business administration and other related laws ${ }^{9}$ and can effectively contain illegal activities. Therefore, it is recommended to introduce and adopt penalties for such professional qualifications in the punishment of infringement.

Based on the characteristics of new plant varieties in breeding and production operations, in order to effectively stop violations of breeder's rights, the following should be added to the tort liability: (i) The infringer cannot apply for or own breeders' rights within 3 years, with an increase to periods of 5, 8, or 10 years for repeated infringement. (ii) The infringer shall not engage in or participate in varieties breeding, seeds production, or related business activities and shall not have the qualifications for production of seeds within the following period of $3,5,8,10,15$, and 20 years. $^{10}$

\subsubsection{To Set Up a System of "Statutory Starting Point for Damages" in Legal Liability}

According to the "Provisions of the Supreme People's Court on the Specific Application of Legal Issues in the Trial of Cases of Disputes over the Violations of New Plant Varieties," the calculation of damages is mainly based on the following four criteria: (i) the actual loss of the infringed person; (ii) the illegal profits obtained by the infringer; (iii) the multiple of the license fee; and (iv) within RMB 3,000,000 the court selects the appropriate amount as compensation according to the circumstances of the case. This is a common calculation standard and method in China's current intellectual property laws, which ranges from" 10,000 to 500,000 yuan" to " 10,000 to 1 million yuan" and to " 10,000 to 3 million yuan." 11

It can be seen that although the specific amount ranges are different, their basic ideas and models have not changed. In reality, for the general case, "the actual losses of the infringed person" and "the illegal profits obtained by the infringer" are all difficult to accurately calculate. So overall, this provision is more of a simple legislative declaration; for those cases not involving license for use, the "multiplier of license fees" has no practical significance. In addition to the above three items, although the law stipulates three ranges of 10,000 to 500,000 yuan, 10,000 to 1 million yuan, and 10,000 to 3 million yuan, each range is quite large. However, in the legislation, there is no detailed refinement or division of specific standards in this scope, which makes this provision less operable.

\footnotetext{
${ }^{9}$ According to Road Traffic Safety Law of the PRC (2011 Amendment), drivers who violate this law should bear the legal responsibility of "being issued warning, paying fine, motor vehicle driving license being temporarily seized or suspended, or being detent." This law is valid throughout China.

${ }^{10}$ At present, no foreign legislation has provisions on legal responsibilities suggested here, which are the author's own proposals based on his estimate of China's social reality.

${ }^{11}$ In China's copyright law, the amount of compensation that the judge can award at his discretion should be within 500,000 yuan; that in patent law is within 1 million yuan; in trademark law it is within 3 million yuan. In China, in general cases of infringement of intellectual property rights, compensation of at least 10,000 yuan will be awarded; less than 10,000 yuan has rarely occurred. Therefore, when judges consider appropriate compensation, they usually begin by considering more than 10,000 yuan.
} 
This kind of situation, whether for the judge or the parties involved, is undoubtedly a difficult problem for anyone who cannot find a standard answer. In this case, regardless of the discretion of the judge, it is difficult for both parties to be satisfied with his discretionary decisions, because the parties' claims and demands are exactly the opposite. After going through lawsuits, many feel that the implementation of rights protection activities is generally worthless. It not only fails to achieve their desired goals, but it even makes them feel that they are far from their desired goal. Because, for these lawsuits, they have to spend time, energy, and money, after the lawsuits, in addition still having difficulty in effectively curbing the other party's infringement, they may be worse off economically. Thus, in addition to the fact that the content of the legislation to stop infringement is too simple, in terms of compensation for losses, the actual amount of compensation is often too low.

To make up for the abovementioned deficiencies, the author proposes to establish a statutory starting point for compensation in legislation. As long as the defendant is found to have committed a tort, he must bear this statutory amount of compensation. On this basis, the actual losses of the plaintiff or the illegal proceeds of the defendant are calculated again.

Establishing the statutory starting point for damages can largely guarantee that the plaintiff can obtain a basic amount of compensation and maintain faith in the implementation of rights protection. The author proposes to establish the following ten levels of statutory starting point in the protection of new plant varieties: (i) 50,000 yuan, (ii) 100,000 yuan, (iii) 150,000 yuan, (iv) 200,000 yuan, (v) 300,000 yuan, (vi) 500,000 yuan, (vii) 800,000 yuan, (vii) 1 million yuan, (ix) 1.5 million yuan, and (x) 2 million yuan. ${ }^{12}$ The reason why different levels should be set up is because different infringers have different infringement hazards. The compensation amount set up is relatively large, because the infringers who violate the breeder's rights usually have higher sales revenue when they produce seeds. ${ }^{13}$ Judges can choose one of the statutory starting points according to the extent and scale of the infringement. In addition, the statutory starting point amount is not affected by the amount of actual loss suffered by the plaintiff. It is independent statutory damages.

\subsubsection{To Set Up Clear Criminal Responsibility}

In China's Criminal Law (1997), the crime of infringement of intellectual property rights was specifically established, but only crimes concerning copyright, trademark rights, patent rights, and trade secrets were stipulated, and crimes for infringing breeders' rights have not been stipulated. However, in reality, some serious violations of breeders' rights constitute crimes in terms of their degree of infringement

\footnotetext{
${ }^{12}$ Yangkun Hou, Legislation Proposal for the Protection of New Animal Variety Rights Law of the People's Republic of China (in Chinese), Beijing: Intellectual Property Publishing House, 2017: 81.

${ }^{13}$ Supreme People's Court Civil Judgment (2014) Min Ti No. 31 (Dunhuang Seed Industry Pioneer Variety Co., Ltd. v. Zhangye Olin Agricultural Science and Technology Development Co., Ltd. and Shihezi Jinshi Seed Industry Co.). The illegal profits obtained by the defendants were RMB $2,650,920$ yuan. The court ruled that all illegal profits must be returned to the plaintiff.
} 
and social harm, but due to lack of corresponding legal provisions in the current legislation, it is difficult to criminally punish such behaviors. Based on the strict nature of the Criminal Law, according to China's current legal provisions, it is difficult to directly add relevant criminal liability clauses in the "Regulations for the Protection of New Plant Varieties" or the "Seed Law." This will require joint efforts with the National People's Congress Standing Committee and other units to facilitate the completion of this work. In terms of specific articles, it is possible to make clear provisions on the conditions for filing a case, what constitutes a crime, and the extent of sentencing, with reference to the existing provisions concerning intellectual property crimes in the Criminal Law.

\subsubsection{To Establish “Unified Jurisdiction of the Same Infringement Series of Cases"}

In reality, there are often interrelated infringers and infringements, which can be divided into three types in China. One is in the same place; for the same breeders' right, there are multiple different infringers and infringements; the second is in different places, for example, in different provinces, there are multiple different infringements and infringers for the same breeders' right; and third, the same infringer has infringed on different breeders' rights.

In this case, if an infringed right holder needs to file independent infringement cases at the defendant's or defendants' location(s) (residence(s)), infringement site(s), and place(s) where the result of a tort took place), then he may need to go to different provinces or different courts in the same province to file lawsuits, respectively. Obviously, this will greatly increase the plaintiff's litigation costs and the difficulty of litigation, objectively benefitting the infringers.

Therefore, the author proposes to establish a new infringement litigation system in legislation, that is, the system of "uniform jurisdiction over the same infringement series of cases." The purpose of establishing this litigation system is that in cases of infringement of a certain authorized variety or set of varieties, regardless of where the infringement occurred and who or how many parties committed the infringement, all cases are subject to the jurisdiction and trial of a single court. The plaintiff needs only to file one case in a suitable court. For different cases, it is only necessary to file an additional case in this same court.

This system has the following advantages: (i) For the plaintiff, it saves a large amount of litigation costs, and the relevant evidence that has been submitted to the court in previous cases is not required to be submitted in any subsequent cases if the relevant evidence has been determined by the court. (ii) For the court, because the plaintiff's situation is already familiar, there is no need to repeatedly review and confirm facts, which will save a lot of energy and resources, improve trial efficiency, and also avoid different understandings of the plaintiff's basic facts in different cases. (iii) In the same or similar cases, verdicts will be basically the same, avoiding different decisions by different courts in separate cases. (iv) It can swiftly and effectively crack down on infringement by different parties across the whole country and fully protect the interests of farmers and breeders. 


\subsubsection{To Add "Special Rights of Farmers"}

In the protection of new plant varieties, the protected owners are the breeders' rights holders. After the varieties have been applied to production and business activities, the main stakeholders are the farmers who have purchased and planted the varieties. Moreover, because each farmer's ability to withstand economic losses is relatively low, so the injury caused to each farmer is even more serious. In reality, infringers often produce and sell imitated seeds in large quantities, so the scope of the affected farmers is relatively wide. However, under the existing legal framework, although farmers are the direct victims of the torts as well as the breeders' rights holders, farmers do not have any right to stop such infringements in their own name and to obtain compensation. Farmers can only lodge a compensation request on the ground that "the seed quality is unqualified" and the applicable law is the Contract Law. However, violation of the contractual agreement can lead to compensation of actual loss, and the amount of such compensation is generally low. ${ }^{14}$ In addition, since this is a contract dispute, farmers have no right to stop the defendant from continuing to commit the infringement, and they cannot claim punitive damages from the defendant.

Based on the legal spirit of fairness and justice, farmers should also have the right to file an infringement action against the infringer in their own name and request that the court order the infringer to stop the infringement and compensate their losses, including direct losses and reasonable returns that are normally available. Only in this way can farmers' legal interests be fully protected. The injured farmers should be the joint plaintiff with the owner of the breeder's rights or be added as joint plaintiff. If the number of farmers is large, they can elect representatives to participate in the proceedings. In order to enable affected farmers to be aware of the infringement cases that have already been initiated, the court should notify the local government, which should issue a circular in the locality to inform farmers about the names and characteristics of the varieties involved, and encourage the affected farmers to join the lawsuit.

\section{Conclusion}

China is the most populous country in the world, with the largest demand for food, vegetables, and fruits, which means that excellent plant varieties and sufficient food production are important factors that China cannot ignore. Therefore, in-depth

\footnotetext{
${ }^{14}$ Intermediate People's Court of Tieling City, Liaoning Province Civil Judgment (2017) Liao 12 Min 840 (Zhao Guoqing v. Changtu Town, Changtu County, Iron Research Seed Shop) involving seed quality dispute. The plaintiff spent RMB 4500 yuan to buy seeds and planted 16 acres of land. Due to the quality of the seeds, the production was reduced. The estimated loss was 52,250 yuan. However, the court's effective judgment only required the defendant to compensate for one-third of the losses, plus the cost of purchasing seeds, totaling 18,917 yuan. The plaintiff's other losses were not compensated. http://www.pkulaw.cn/Case/pfnl_a25051f3312b07f396d6a91f52f22fcc56d620afd628d2f [2017-06-20/2018-07-19].
} 
research on the issue of new plant varieties and the establishment of reasonable legislative protection are also important.

At present, the main problems facing China in this regard are concentrated in three aspects.

First, the theoretical research on the protection of new plant varieties is relatively superficial. At present, it mainly translates and introduces the contents of the UPOV Convention, as well as some foreign research articles. It has not yet established its own theoretical content in line with China's national conditions.

The second problem is that China's current legislation is relatively backward and cannot meet China's current social needs. It should be revised and improved as soon as possible by participating in the 1991 UPOV Convention and adding some reasonable new content.

The third is the unscientific production and management philosophy that prevails in China's current society - "money may be obtained by unscrupulous means" which induces many businesses to infringements and other illegal acts in pursuit of their own economic interests.

\section{References}

Gansu Province Anti-Counterfeiting Work Network. The supervision of the seed market in Jiuquan City (2015-11-20)[2018-04-20].

Guo, J. (2006). Study on DNA fingerprint identification standard of derived maize varieties. Agricultural Boreali Sinila, 21(1), 47.

Xiaonan, W. International Legislation of Farmers' Rights in the Protection of New Plant Varieties and for Reference, World Agriculture: 2015(11)12-14.

Yangkun, H. (2015). On the characteristics and legal functions of the names of new plant varieties. Intellectual Property Rights, (9), 37-43. (in Chinese).

Yangkun, H. (2017). Legislation proposal for the protection of new animal variety rights law of the People's Republic of China (p. 81). Beijing: Intellectual Property Publishing House. (in Chinese).

Yun, W. The "crimes against new plant variety rights" should be added to the criminal law, Peasant Daily, 2015-03-16 (006).

Open Access This chapter is licensed under the terms of the Creative Commons Attribution 4.0 International License (http://creativecommons.org/licenses/by/4.0/), which permits use, sharing, adaptation, distribution and reproduction in any medium or format, as long as you give appropriate credit to the original author(s) and the source, provide a link to the Creative Commons license and indicate if changes were made.

The images or other third party material in this chapter are included in the chapter's Creative Commons license, unless indicated otherwise in a credit line to the material. If material is not included in the chapter's Creative Commons license and your intended use is not permitted by statutory regulation or exceeds the permitted use, you will need to obtain permission directly from the copyright holder.

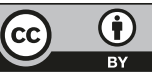

